\title{
Mechanism of two Way Shape Memory Effect Obtained by Stabilised Stress Induced Martensite
}

\author{
J.M. Guilemany and J. Fernández
}

Metalurgia Física-Cienca de Materiales, Dept. de Ingeniería Química y Metalurgia, Facultad de Química, Martí i Franquès, 1. E-08028 Barcelona, Spain

\begin{abstract}
Two Way Shape Memory Effect (TWSME) involves thermomechanical routines which produce some plastic deformation or complex dislocation arrays during the training procedure. The results of TWSME obtained by these thermomechanical training routines are not as good as would be expected because new dislocations are generated during thermal cycling. These dislocations may interact with those that provide TWSME to the alloy. The present authors have developed a completely new training method which involves the stabilisation of the stress induced martensite (SSIM). The present work has been carried out to improve knowledge of the mechanism of TWSME obtained by the SSIM training method. The results show that the new training method not only improves the values of TWSME but also gives improved stability to this TWSME.
\end{abstract}

\section{INTRODUCTION}

In the last three years, different training routines have been developed to give the Two Way Shape Memory Effect (TWSME) all of them based on the repetitivity of a thermomechanical training routine (1-3). These new methods attempt to improve the results of TWSME by conventional training routines which have been extensivelly used previously (4-7). Each of them is based on the generation of dislocations, during the training procedure, which remain in the material in the subsequent thermal cycles so providing TWSME.

On the other hand, thermal cycling generates new dislocations which interact with those that provide TWSME, which means that there is a reduction in TWSME.

$\mathrm{Ni}$-Ti alloys are trained in a completelly different way when compared with the methods used for copper based alloys (8-10). Ni-Ti alloys are trained by constrained ageing between $300^{\circ}$ and $500^{\circ} \mathrm{C}$ for 1 hour. This kind of training process provides not only TWSME but also AllRound Shape Memory Effect (ARSME).

Complex Ni-rich precipitates are formed during ageing these alloys (11) (12). These precipitates produce internal stress fields which control the growth of the martensite variants providing TWSME or ARSME. However, Liu and McCormick (13) and Todoroki et al. (14) have found that the presence of the $R$ phase during the martensitic transformation in Ni-Ti alloys leads to a lower TWSME.

A training process based on the stabilisation of the stress induced martensite (SSIM) has also been developed, in recent years, for Cu-based alloys (15-20). The aim of the present work 
is to improve our knowledge of the mechanism of TWSME obtained by SSIM in a polycrystalline $\mathrm{Cu}-\mathrm{Zn}-\mathrm{Al}-\mathrm{Co}$ alloy.

\section{EXPERIMENTAL METHOD}

Two $\mathrm{Cu}$ based alloys have been prepared by melting high purity metals in a vacuum sealed quartz tube. The ingot was subsequently homogeneised at $850^{\circ} \mathrm{C}$ for 12 hours and hot rolled into $0.5 \mathrm{~mm}$ thick plates. Alloy compositions in wt \% together with the $\mathbf{M}_{\mathrm{s}}$ temperature are shown in Table I.

Table I. Alloy compositions and $\mathbf{M}_{\mathrm{s}}$ temperatures.

\begin{tabular}{|c|c|c|c|c|c|}
\hline ALLOY & $\mathrm{Cu}$ & $\mathrm{Zn}$ & $\mathrm{Al}$ & $\mathrm{Co}$ & $\mathbf{M}_{\mathrm{s}}\left({ }^{\circ} \mathrm{C}\right)$ \\
\hline 1 & 72.5 & 20.2 & 6.6 & 0.7 & 30 \\
\hline 2 & 73.9 & 18.9 & 6.7 & 0.5 & 5 \\
\hline
\end{tabular}

Several samples $70 \mathrm{~mm}$ long $\times 5 \mathrm{~mm}$ wide $\times 0.5 \mathrm{~mm}$ thick were cut from the sheets and trained by SSIM method, previously described (18-20). Samples taken from alloy 1 have been trained at different temperatures between 50 and $240^{\circ} \mathrm{C}$ with an interval of $10^{\circ} \mathrm{C}$. Samples taken from alloy 2 have been trained from 30 to $170^{\circ} \mathrm{C}$ with an interval of $20^{\circ} \mathrm{C}$.

Samples which were untrained and trained by treatments at 100,150 and $200^{\circ} \mathrm{C}$, for alloy 1 , and by treatments at 130 and $170^{\circ} \mathrm{C}$, for alloy 2 , have been examined by optical and TEMSTEM. For the TEM examination, discs $3 \mathrm{~mm}$ in diameter have been prepared by cool ion beam at $4 \mathrm{kV}$ with an initial tilt of $10^{\circ}$ and a final tilt of $5^{\circ}$. A TEM-STEM Hitachi H-800-MT equipped with and EDS X Ray microanalysis system have been used ( $200 \mathrm{kV})$.

\section{RESULTS AND DISCUSSION}

Both alloys contain three kinds of Co-rich precipitates before training, as has been previously described (21). The original $B$ phase of alloy 2 before training is shown in Figure 1 . Small amount of martensite can be seen near the grain boundaries. This martensite has appeared as a consequence of the nucleation effect that grain boundaries have, in locally raising the $M_{s}$ above room temperature.

Once the samples are trained, eg. $\mathrm{T}_{\text {training }}=150^{\circ} \mathrm{C}$, they exhibit a large amount of stabilised stress induced martensite, see Figure 2, and subsequently show TWSME. Thus, TWSME could be related with the presence and the amount of the SSIM obtained during training (18) (22).

Similar results have been obtained for alloy 1. But it is not possible to distinguish between the initial martensite and SSIM because the alloy is almost fully martensitic before training. However, samples trained have fewer martensite variants than the untrained ones, meaning that the thermal martensite, which appeared on cooling, has nucleated and grown under the influence of the SSIM.

The structure of alloy 1 trained at $100^{\circ} \mathrm{C}$ for 30 minutes is shown in Figure 3. A large quantity of $\gamma$ precipitates are seen having an average size of $10-15 \mathrm{~nm}$. Other samples trained at 150 and $200^{\circ} \mathrm{C}$ also have $\gamma$ precipitates with a size of $15-25 \mathrm{~nm}$ and $20-30 \mathrm{~nm}$, respectively. Trained samples of the alloy 2 also exhibit $\gamma$ precipitates, Figure 4, with a size of $15-20 \mathrm{~nm}$ in the case of the sample trained at $170^{\circ} \mathrm{C}$ for 30 minutes.

A particular characteristic is that, in all cases, these $\gamma$ precipitates contain cobalt in their composition (21). 
Coherency strain fields were observed after treatment at temperatures up to $170^{\circ} \mathrm{C}$, Figure 5 , but after treatment at $200^{\circ} \mathrm{C}$ the coherency strain fields were absent.

The matrix is supersaturated with respect to cobalt since the alloy is quenched from $850^{\circ} \mathrm{C}$ prior to the training treatment. During the training procedure, the matrix rejects the excess Co in the form of small coherent precipitates.

Hence, the $\gamma$ precipitates, which also form during training, nucleate heterogeneoulsy on the coherent Co precipitates, although they can also nucleate homogeneously. The first type of nucleation is energetically favoured, thus, most $\gamma$ precipitates are heterogeneously nucleated and show a central Co rich core.

The process of $\gamma$ precipitation on coherent cobalt precipitates is accelerated by increasing the training temperature. Thus, with the sample trained at $200^{\circ} \mathrm{C}, \gamma$ has precipitated on almost all the Co particles so that coherency strain fields are no longer visible (21).

De Graef et al. (23) have found small $\gamma$ precipitates at the martensite plate boundaries after ageing a cobalt free $\mathrm{Cu}-\mathrm{Zn}-\mathrm{Al}$ alloy at $100^{\circ} \mathrm{C}$ for 3 days. The difference in time for precipitation may be attributed to the fact that the Co precipitating from the supersaturated matrix the matrix accelerates the precipitation of $\gamma$ by heterogeneous nucleation.

The \% of TWSME is directly related to the amount of SSIM as can be seen from Figure 2 and Table II (18). The presence of the stabilised stress induced martensite allows the nucleation and growth of particular martensite variants so providing TWSME.

Table II. \% of TWSME for the different training temperatures $\left({ }^{\circ} \mathrm{C}\right.$ ) during cycling $(\mathrm{N})$ for alloy 2 .

\begin{tabular}{|c|c|c|c|c|c|c|c|c||}
\cline { 2 - 9 } \multicolumn{1}{c|}{} & \multicolumn{8}{c|}{ \% TWSME } \\
\hline $\mathrm{N}$ & $30^{\circ} \mathrm{C}$ & $50^{\circ} \mathrm{C}$ & $70^{\circ} \mathrm{C}$ & $90^{\circ} \mathrm{C}$ & $110^{\circ} \mathrm{C}$ & $130^{\circ} \mathrm{C}$ & $150^{\circ} \mathrm{C}$ & $170^{\circ} \mathrm{C}$ \\
\hline 1 & 17 & 30 & 37 & 52 & 68 & 60 & 60 & 61 \\
\hline 10 & 17 & 32 & 40 & 52 & 68 & 60 & 60 & 61 \\
\hline 100 & 20 & 32 & 37 & 55 & 65 & 57 & 63 & 61 \\
\hline
\end{tabular}

The precipitation of $\gamma$ plays an important role because it stabilises the stress induced martensite by local depletion of $\mathrm{AI}$ and $\mathrm{Zn}$ from the matrix so raising the $\mathrm{M}_{\mathrm{s}}$ temperature. At the same time, the precipitates make it difficult for the martensite to retransform. Thus the $M_{s}$ is raised by mechanical impingement.

\section{CONCLUSIONS}

1.- The stabilised stress induced martensite provides the two way shape memory effect by promotion of particular martensite variants.

2.- The stabilised stress induced martensite can be obtained by $\gamma$ precipitation during the training procedure. This precipitation is aided by the presence of Co precipitates formed from the supersaturated matrix.

3.- The $\gamma$ precipitates deplete the matrix of $\mathrm{Al}$ and $\mathrm{Zn}$ locally raising the martensitic transformation temperature. They also have an impingement effect which mechanically increases the $M_{s}$. 


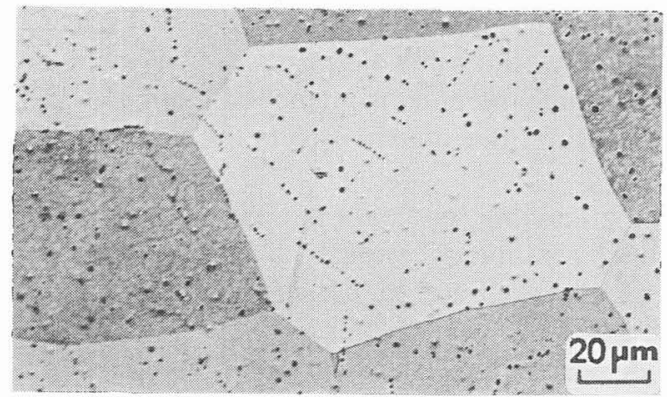

Figure 1. Original $B$ structure of the alloy 2.

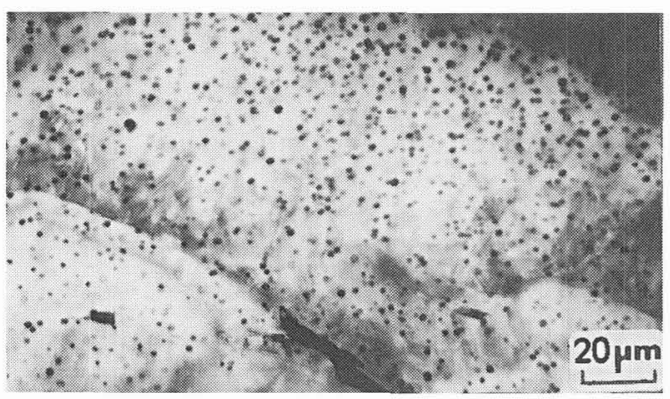

Figure 3. Gamma precipitates present in the trained alloy 1 .

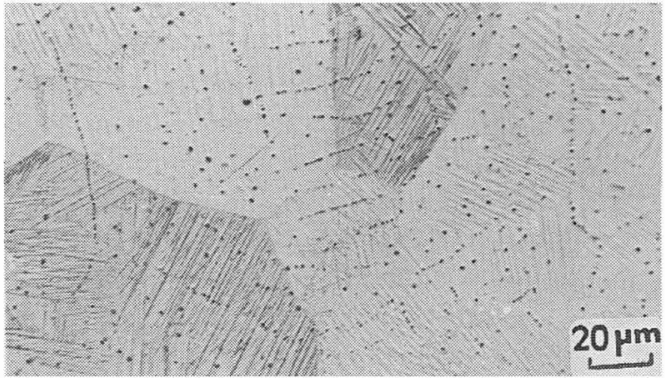

Figure 2. Structure of the sample aged at $150^{\circ} \mathrm{C}$ (alloy 2) with the presence of SSIM.

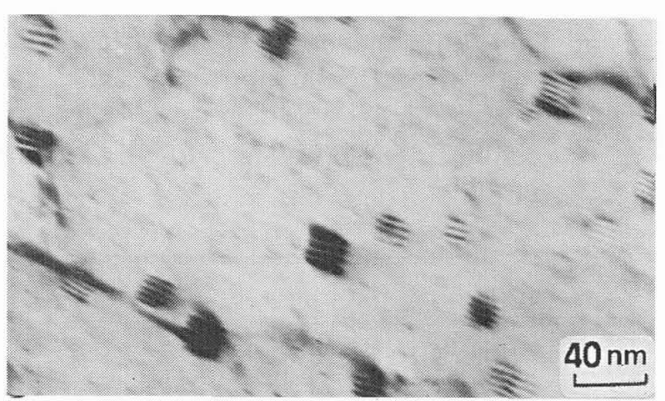

Figure 4. Gamma precipitates found in the trained alloy 2 .

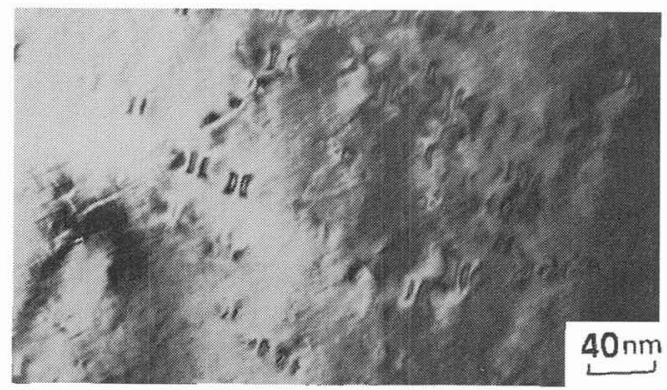

Figure 5. Coherency strain fields formed during the training of alloy 2. 


\section{ACKNOWLEDGEMENTS}

The authors acknowledge the CICYT of SPAIN for finnancial support to carry out this work, under the Project MAT92-1025-CO2-02. They also acknowledge Prof. J. Nutting in sabathical year in the University of Barcelona (CICYT SAB93-0020) for his careful and critical reading of the paper.

\section{REFERENCES}

[1] Flores Zúñiga H., Belkahla S., Guénin G., " The thermal ageing and two way memory effect (TWME) in Cu-Al-Be shape memory alloy ", Martensitic Transf. and Shape Memory properties, Aussois (France), 16-18 September, 1991, pp. 289-294.

[2] Morris M. A., Acta Met. et Mater., 40, (1992), pp. 1573-1586.

[3] Stalmans R., Van Humbeeck J., Delaey L., Materials Transactions JIM, 33, (1992), pp. 289-293.

[4] Wasilewski R. J., Scripta Met., 9, (1975), pp. 417-422.

[5] Schroeder T. A., Wayman C. M., Scripta Met., 11, (1977), pp. 225-230.

[6] Perkins J., Materials Science and Engineering, 51, (1981), pp. 181-192.

[7] Duerig T. W., Albrecht J., Gessinger G. H., Journal of Metals, (1982), pp. 14-20.

[8] Nishida M., Honma T., Scripta Met., 18, (1984), pp. 1293-1298.

[9] Nishida M., Honma T., Journal de Phys., Colloque C4, suppl. au n $n^{a}$ 13, 43, (1982), pp. 225230.

[10] Nishida M., Wayman C. M., Scripta Metall., 18, (1984), pp. 1389-1394.

[11] Nishida M., Wayman C. M., " $\mathrm{R}$-phase type transformation of $\mathrm{Ti}_{2} \mathrm{O}_{3}$ precipitates in aged Ti-52 at\% Ni ", Proc. Int Conf. on Mart. Transformation, ICOMAT'86, Nara (Japan), 1986 , pp. 653-658.

[12] Honma $T_{\text {., " }}$ The effect of ageing on the spontaneous shape change and the all-round shape memory effect in Ni-rich TiNi alloy", Proc. Int. Conf. on Mart. Transformation, ICOMAT'86, Nara (Japan), 1986, pp. 585-590.

[13] Liu Y., McCormick P. G., Materials Science Forum, 56-58, (1990), pp. 585-590.

[14] Todoroki K., Tamura H., Suzuki Y. " Variable temperature stress-induced martensitic transformation training of Ni-Ti alloy ", Proc. Int. Conf. on Mart. Transformation, ICOMAT'86, Nara (Japan), 1986, pp. 748-753.

[15] Rapacioli R., Torra V, Cesari E., Guilemany J. M., Miguel J. R., Scripta Metall., 22, (1988), pp. 261-264.

[16] Lee I. Ch., Chung I. S., Scripta Metall., 23, (1989), pp. 161-166.

[17] Leu S. S., Hu C. T., Scripta Metall., 23, (1989), pp. 1925-1930.

[18] Guilemany J. M., Fernández J., Mellor B. G., Scripta Metall. et Mater., 24, (1990), pp. 1941-1945.

[19] Guilemany J. M., Mellor B. G., Fernández J., J. of Materials Science Letters, 11, (1992), pp. 964-967.

[20] Guilemany J. M., Fernández J., Scripta Metall. et Mater., 30, (1994), pp. 59-61.

[21] Guilemany J. M., Fernández J., Scripta Metall. et Mater, 30, (1994), pp. 319-323.

[22] Guilemany, J. M., Rapacioli R., Miguel J. R., Inst. Phys. Conf. Ser., 2 (13), EUREM 88, (1988), pp. 491-492.

[23] De Graef M., Van Humbeeck J., Dealey L., " TEM observations of stabilised Cu-Zn-A1 martensite ", Proc. Int. Conf. on Mart. Transformation, ICOMAT'86, Nara (Japan), 1986, pp. $850-855$. 